\title{
Evaluation of Patient- and Parent-Rated Emotional Expression Using the Expression and Emotion Scale for Children (EESC) in an Observational Study of ADHD in Children and Adolescents
}

\author{
Alexander Schacht ${ }^{*}, 1$, Arne Bürger ${ }^{2}$, Peter M. Wehmeier ${ }^{3,4}$ and Michael Huss ${ }^{2}$ \\ ${ }^{1}$ Lilly Deutschland GmbH, Medical Department, Werner-Reimers-Str. 2-4, D-61352 Bad Homburg, Germany \\ ${ }^{2}$ Child and Adolescent Psychiatry and Psychotherapy, University of Mainz, Langenbeckstr. 1, D-55131 Mainz, Germany \\ ${ }^{3}$ Vitos Hospital for Psychiatry and Psychotherapy, Weilstr. 10, 35789 Weilmünster, Germany \\ ${ }^{4}$ Department of Child and Adolescent Psychiatry, Central Institute of Mental Health, University of Heidelberg, J5, \\ Mannheim, D-68159, Germany
}

\begin{abstract}
Background: The assessment of emotional expression in patients with ADHD can differ between parent/caregiver and child. Therefore, a new patient-rated version of the Expression and Emotion Scale for Children (EESC) was created and psychometrically analysed.

Methods: This is a 6-month follow-up data analysis of a multicenter, prospective, 12-month observational study in children and adolescents with ADHD. Agreement between the two EESC versions (patient- and parent-rated), internal consistency, sensitivity for changes, floor and ceiling effects as well as test-retest variability were evaluated. The relationship between both EESC scores and the physician-rated ADHD-rating scale (ADHD-RS), Clinical Global Impression of Severity (CGI-S), and General Impression of Percieved Difficulties (GIPD) were also calculated.

Results: 504 patients (mean age 9.6 years) were included and treated with non-stimulant medication $(\mathrm{n}=252)$ or stimulant medication ( $\mathrm{n}=247) ; 5$ patients received both medications. The EESC scores decreased similarly for patients and parents and in parallel over time by about 15 points, with the patient EESC scores being always about 3-4 points less than the parent-rated score. Both satisfaction scores increased in parallel by 2-3 points. The agreement and the correlation between the two EESC versions were in a modest range of approximately 0.5 to 0.6 and stable over time. The item-total correlations and analysis of Cronbach's Alpha showed mostly good support of the different items for the total scores, except items 19 and $24(\mathrm{r}<0.1)$. Ceiling and floor effects and the amount of missing items were limited. Test-retest variability and sensitivity for changes was moderate to excellent $(r>0.48)$. Correlations between the EESC score and other ADHD scales (ADHD-RS, CGI-S) were small to moderate for both ratings. The correlation between the GIPD and the EESC within raters was constant over time $(r \approx 0.5)$.

Conclusion: This analysis showed that both EESC versions have sound psychometrical properties and can be used in routine settings.
\end{abstract}

Trial Registration Number: ClinicalTrials.gov Identifier: NCT00540826.

Keywords: ADHD, Expression and Emotion Scale for Children (EESC), agreement, patient-rated, parent-rated, internal consistency, sensitivity for changes, floor and ceiling effects, test-retest variability, validation.

\section{BACKGROUND}

Approximately 3\%-7\% of school-age children are affected by attention-deficit/hyperactivity disorder (ADHD) which is characterized by inattention, impulsivity and hyperactivity [1]. Beyond these symptoms, ADHD is associated with significant impairment of cognitive and psychosocial functioning [2-5] and has a negative impact on the quality of life (QoL), both in patients and their families [6-11].

*Address correspondence to this author at the Lilly Deutschland $\mathrm{GmbH}$, Werner-Reimers-Str. 2-4, D-61352 Bad Homburg, Germany; Tel: +496172-273-2728; Fax: +49-6172-273-2182;

E-mail: schacht_alexander@lilly.com
Psychostimulants are effective in the treatment of ADHD, especially in combination with behavioural therapy, as reported in the Multimodal Treatment Study of ADHD (MTA study) [12]. The non-stimulant atomoxetine is also effective in the treatment of children and adolescents with ADHD $[13,14]$. Most trials studying these compounds focus on the core symptoms of the disease reported by the physician and/or the parent and the tolerability of the medications. More recently, some research has focused on the QoL beyond the core symptoms of the disease [15-19]. Health-related QoL is a multidimensional concept that reflects the subjective physical, social, and psychological aspects of health and is distinct from symptoms of the disorder and objective functional outcomes [20]. The 
measure of these factors is decisive in the development of comprehensive care therapies and medical interventions.

Generic questionnaires such as the Child Health and Illness Profile - Child Edition (CHIP-CE) [21] and the Child Health Questionnaire (CHQ) [22] have been used. These questionnaires provide valuable information especially for decisions on health resources, as they can provide comparative data on different disorders. The downside of such a general approach is the complexity of these questionnaires, e.g., some domains may not be affected or of interest, like physical domains in psychiatry. Another disadvantage is the possible low specificity regarding disease-specific problems.

Emotional expression can be viewed as one specific component of QoL that has particular importance for ADHD, as the restriction of emotional expression, also known as blunting, is a commonly reported but understudied side effect of stimulants [23]. Restricted emotional expression has previously been reported as appearing "dull or overly restricted" [24], appearing like a "zombie" [25], experiencing "personality blunting" [26], or of "not feeling like themselves" [27]. Perwien et al., developed the parentrated Expression and Emotion Scale for Children (EESC) based on this construct [23]. Whereas parent assessment is an important aspect to measure both core symptoms as well as aspects of QoL, patient assessment can complement this information and provide additional insight into symptoms and QoL. Because this assessment might differ between parent/caregiver and child, it is relevant to be able to obtain subjective information from the child. Therefore, a new patient-rated version of the EESC was created for this study.

One of the secondary research objectives of the present study was to evaluate the parent- and the newly devised patient-rated versions of the EESC in an observational setting and to compare it with other scales used in this study. The focus of this publication is to answer this secondary objective.

The primary research objective of this observational study was to evaluate treatment compliance over one year in children and adolescents with ADHD in a routine clinical setting. Only a small number of observational studies have been undertaken to assess compliance with ADHD medication in routine clinical settings [28-31]. Given the importance of compliance in the treatment of ADHD [32], further research on compliance with ADHD medication is clearly important $[33,34]$.

An observational study is especially useful in evaluating the EESC as it facilitates to explore the characteristics of the scale in a population being close to normal practice and thus being more heterogeneous than populations normally studied in clinical trials. The strict inclusion and exclusion criteria of clinical trials result in highly selected samples of patients regarding various factors, e.g., comorbid disorders, concomitant therapy, and symptom severity. However, in clinical practice, ADHD medication is used in a much broader range of patients. Furthermore, sites with lower levels of bureaucracy may participate in observational studies, as compared with sites participating usually in clinical studies. Also, it is important to detect problems of a scale that may only be seen in a minimally regulated setting with little training provided to the sites. The characteristics of a scale should be robust enough to be sustained in a realworld setting. This will also ensure that the scale will have good properties in the more regulated setting of a clinical trial. The present article reports the psychometrical properties of the newly devised patient-rated version of the EESC in comparison to the original parent-rated EESC.

\section{METHODS}

\section{Study Design and Study Population}

The results presented here are based on a prospective, 12month, observational, non-interventional, open-label study that was carried out in Germany. The study was still ongoing during the analysis presented below and thus only data up to 6 months follow-up are presented. Children and adolescents, aged 6-17 years, with a diagnosis of ADHD according to ICD-10 [35] or DSM-IV [1] criteria, and who were newly initiated on a medication approved for the treatment of ADHD were included in the study. Since ecological validity was intended to be optimized, the diagnosis of ADHD was given by the clinician according to practice guidelines, but was not confirmed by standardized diagnostic instruments. The diagnostic process should be as naturalistic as possible reflecting the current daily practice of the clinician. All patients were not previously treated with any ADHD medication. All treatment decisions, e.g., the choice of the approved medication, the dose, stopping of medication, or augmenting medication during the study were left to the discretion of the investigator. No further in- or exclusion criteria were specified. The responsible Ethics Committee approved the study and all patients and parents participating in the study were fully informed and gave written informed consent for the release of information according to local regulations. More details of the study design are accessible on the internet via the Lillytrials.com and clinicaltrials.gov websites.

\section{Data Collection}

Data were collected at an initial baseline visit, after week 1 and week 2, and after 1, 3, 6, 9, and 12 months. However, this analysis is restricted to 6-month follow-up data as this analysis was performed when the study was ongoing and final result publication is under preparation. At the initial visit, the investigator documented patient characteristics, medical history of ADHD, and presence or absence of solicited psychiatric comorbidities (anxiety, tic/Tourette syndrome, depression, other psychiatric diseases). The patient's psychosocial situation was assessed using Axis 5 items of the ICD-10 Multiaxial Classification [36]; additional data were collected regarding the family's socioeconomic background. The investigator rated the patient's level of intelligence, according to Axis 3 of the ICD-10 Multiaxial Classification (very high: IQ $>129$; high: IQ 115129; average: IQ 85-114; low: IQ 70-84; IQ unknown). The type and dose of the newly prescribed ADHD-medication as well as the reasons for choice of medication were recorded. For assessment of disease severity, the Attention- 
Deficit/Hyperactivity Disorder Rating Scale (ADHD-RS) $[37,38]$ and the Clinical Global Impression-Severity (CGIS) $[39,40]$ were used at each visit. Data related to quality of life were also recorded at each visit, using the Global Impression of Perceived Difficulties (GIPD) instrument [41]. The GIPD is a five-item rating of ADHD-related difficulties, assessing (a) difficulties in the morning, (b) difficulties during school, (c) difficulties completing homework, (d) difficulties in the evening, and (e) overall difficulties over the entire day and night. Each item is rated from 1 to 7 ( $1=$ not at all difficult, $7=$ extremely difficult) and reflects the situation during the past week. The GIPD total score was derived using the mean of the 5 items. The items are rated separately by patient, parent (or primary caregiver), and physician, allowing comparisons of the different perspectives. In addition, emotional expression was assessed at each visit, using the parent-rated Expression of Emotion Scale for Children (EESC) [23]. The EESC consists of 29 items rated from 1 to $5(1=$ does not apply at all, $5=$ applies fully). Higher scores represent higher impairment in expression of emotions.

Since emotional states of the child may be different from those expressed by the parent/caregiver, we wanted to assess the constructs covered by the EESC from a subjective viewpoint. Initially, 4 children were chosen to change the wording of the adult version of the EESC. We used a semistructured interview technique to explore basic aspects of readability and acceptance in children. We also asked the child to explain in his or her own words the meaning of each item. The changed items were then given to 26 additional children instructing them to interpret the items. At least $80 \%$ of the children would be expected to fully understand the original meaning. It was expected that not more than $20 \%$ of the children would mostly understand the original intention, but not contradict the context. Finally, child psychiatrists and psychologists were asked to match the changed items with the original items from the parent version. This was done in order to establish that the changed items represented the same meaning as in the adult version.

\section{Statistical Analysis}

The sample size was determined for the primary endpoint and is explained in another publication [42]. 504 patients were included in the study.

All tests of statistical significance were carried out at a nominal level of $5 \%$ using two-tailed test procedures. Twosided confidence intervals (CIs) were computed using a $95 \%$ confidence level. Demographic characteristics and baseline variables as well as EESC total scores (parent- and patientrated) and the two patient-rated satisfaction scores over time were analysed using descriptive statistics (mean and standard deviation (SD) if not mentioned otherwise). Agreement between EESC total scores as rated by the parent and the patient was evaluated using a weighted version (SAS default option: Cicchetti-Allison type) of Cohen's Kappa with 95\% $\mathrm{CI}$ and also using Spearman's correlation coefficient with 95\% CI, which were computed at each time point using data from all patients. The same was done on an item basis, but to reduce space only the minimum and the maximum value of the different time points were displayed. The internal consistency of the EESC parent and patient total scores were explored using Cronbach's Alpha for patient and parent ratings as well as item-total correlation using Spearman's version of the correlation coefficient. Again, only minimum and maximum values of the different time points are shown. Floor and ceiling effects and number of missing ratings for the EESC total scores are presented for all visits. As the extreme cases are mostly observed at the first and the last visit, i.e., baseline and 6-month visit, only these results are displayed for the items. Spearman's correlation coefficient and Cohen's weighted Kappa (both with 95\% CIs) were used to assess test-retest variability and sensitivity for changes between consecutive visits for the EESC total score for both ratings. Spearman's correlation coefficient with 95\% CIs was also used to explore the relationship between EESC total score as rated by the parent and the patient and ADHD symptoms as measured by the physician-rated ADHD-RS total score, hyperactivity/impulsivity subscore, inattention subscore, and the CGI-S for ADHD over time for all patients. Finally, Spearman's correlation coefficient with 95\% CI between EESC total score and GIPD total score within parent and patient ratings explore the relationship between the EESC being a specific scale and the GIPD being a less specific scale without having problems with differences between raters. All correlation analyses were repeated using Pearson's version of the correlation coefficient. However, as the results were similar, only Spearman's version, which is based on ranks, is shown.

\section{RESULTS AND DISCUSSION}

\section{Results of EESC Patient Version Development}

A total of 26 children with an average age of 12 years $(\mathrm{SD}=3.2)$ were asked to interpret the adult version of the EESC. It was found that 17 of the 29 items were correctly interpreted by the children according to the intent of the adult version. Four of the items had to be changed because the children could not translate the full meaning of the item. Eight items could not be fully translated by any of the children, most likely due to the differing age groups. Changes were carried out with the children who did not understand the original meaning of the items by explaining the meaning in a manner understandable to that age group. Finally, all 26 children were asked to reinterpret the 12 misunderstood items. All 12 items were appropriately perceived by the children in accordance to the intention of the adult version.

Twelve child and adolescent psychiatrists or psychologists, with experience not only in a clinical setting but also with diagnostic experience, were asked as experts to match the changed items to the original items in the parent version of the EESC. Twenty-seven of the 29 changed items were correctly matched by at least $90 \%$ of the experts. Items 2 and 22 were often interchanged, with only $60 \%$ matching the original item. In conclusion, it could be determined that the comprehensibility, as seen in the results of the expert rating, shows the child version of the EESC to be equivalent to the adult version. 


\section{Results of COMPLY}

A total of 504 patients were recruited throughout Germany at 83 investigational sites ( 316 by paediatricians, 183 by child and adolescent psychiatrists, 3 by primary care physicians, and 2 by adult psychiatrists). The diagnoses of the patients were documented either according to ICD-10 or according to DSM-IV criteria. Of those diagnosed according to DSM-IV criteria $(n=70)$, the combined type of ADHD was diagnosed in $22(31.4 \%)$ of all patients, whilst the "predominantly inattentive" subtype was diagnosed in 27 (38.6\%), and ADHD combined type with conduct disorder in $12(17.1 \%)$ of all patients. Of those patients diagnosed according to ICD-10 criteria $(n=434)$, a total of $226(52.1 \%)$ patients were diagnosed with "disturbance of activity and attention" and $155(35.7 \%)$ patients were diagnosed with "hyperkinetic conduct disorder". The diagnostic subgroups "ADHD without hyperactivity" and "other hyperkinetic disorders" were small (43 and 10 individuals, respectively). Two hundred and fifty-four patients reported at least one psychosocial issue as defined by Axis 5 of the ICD-10 classification system. Of those patients, most had problems related to education and literacy (Axis 5 item 8.2) $(n=135$, $53.2 \%$ ), educational maladjustment and discord with classmates/workmates (Axis 5 item 8.0) $(n=121,47.6 \%)$, lived in an atypical parenting situation (Axis 5 item 5.1) $(\mathrm{n}=109,42.9 \%)$, or had educational maladjustment and discord with the teacher/boss (Axis 5 item 8.1) $(n=84$, $33.1 \%)$.

Out of all patients $(n=504)$, psychiatric comorbidities were reported in $245(48.6 \%)$ patients, conduct disorder in $108(21.4 \%)$ patients, oppositional defiant disorder in 95 (18.9\%) patients, anxiety disorder in $47(9.3 \%)$ patients, tic disorder in $29(5.8 \%)$ patients, depression in $24(4.8 \%)$ patients, and other psychiatric comorbid disorders in 57 (11.3\%) patients.

A total of $252(50.0 \%)$ patients were initiated on treatment with atomoxetine and $247(49.0 \%)$ with stimulant medication (short and/or long-acting methylphenidate). Both types of medication were prescribed concomitantly in 5 patients $(1 \%)$.

Concomitant drug therapy (multiple naming possible) was prescribed in 19 patients. The large majority of patients $(n=485,96.2 \%)$ did not receive any concomitant medication for their psychiatric disorders. More than $98 \%$ of the patients claimed not to use any alcohol, tobacco, recreational drugs, or any other illegal drugs.

Non-drug concomitant therapy was prescribed in 353 $(70.0 \%)$ of the 504 patients, with psychotherapy/psychotherapeutic counselling $(n=247,49.0 \%)$, educational measures $(n=181,35.9 \%)$, occupational therapy $(n=83$, $16.5 \%)$, and behaviour therapy $(n=57,11.3 \%)$ being the most often applied therapies $(>10 \%$ each). Commonly reported non-drug therapies used prior to study start were applied in $311(61.7 \%)$ of the 504 patients: occupational therapy $(n=168,33.3 \%)$, educational measures $(n=159,31.6 \%)$, and psychotherapy/psychotherapeutic counselling $(n=146$, $29.0 \%$ ) were reported most often $(>10 \%$ each) (see also Table 1).

\section{Measures}

The mean EESC total scores decreased similarly for patients and parents and in parallel over 6 months by about 15 points. The patient-rated mean total score of the EESC was always about 3 to 4 points less than the parent-rated score. Furthermore, the SD for the patient-rated total score was about 1 to 2 points less than the parent-rated version. Both satisfaction scores increased in parallel by approximately 2 to 3 points (see Table 2).

Table 1. Patient Baseline Demographics and Characteristics

\begin{tabular}{|c|c|}
\hline All Patients $(\mathrm{N}=504)$ & \\
\hline \multicolumn{2}{|l|}{ Gender } \\
\hline Male, n (\%) & $366(72.6)$ \\
\hline Female, n (\%) & $138(27.4)$ \\
\hline Age [years], mean (SD) [min, max] & $9.6(2.6)[6,17]$ \\
\hline \multicolumn{2}{|l|}{ Educational status, n (\%) } \\
\hline Pre-school & $9(1.8)$ \\
\hline Kindergarten & $14(2.8)$ \\
\hline Elementary School & $301(59.7)$ \\
\hline Middle School & $47(9.3)$ \\
\hline High School & $56(11.1)$ \\
\hline Vocational training & $3(0.6)$ \\
\hline College & $44(8.7)$ \\
\hline Special Education School & $29(5.8)$ \\
\hline None & $1(0.20)$ \\
\hline Time since onset of disorder [years], mean (SD) & $4.8(3.0)$ \\
\hline \multicolumn{2}{|l|}{ DSM-IV, n (\%)* } \\
\hline ADHD, combined type & $22(31.4)$ \\
\hline ADHD, predominantly inattentive & $27(38.6)$ \\
\hline $\mathrm{ADHD}$, predominantly hyperactive-impulsive & $7(10.0)$ \\
\hline ADHD, combined type + conduct disorder & $12(17.1)$ \\
\hline ADHD, combined type + oppositional defiant disorder & $2(2.9)$ \\
\hline \multicolumn{2}{|l|}{ ICD-10 Codes, $\mathrm{n}(\%)^{*}$} \\
\hline F90.0 Disturbance of activity and attention & $226(52.1)$ \\
\hline F90.1 Hyperkinetic conduct disorder & $155(35.7)$ \\
\hline F98.8 Attention deficit disorder without hyperactivity & $43(9.9)$ \\
\hline F90.8 Other hyperkinetic disorders & $10(2.3)$ \\
\hline
\end{tabular}

As shown in Table $\mathbf{3}$, the agreement and the correlation between the newly devised patient and the parent total score was more or less stable over time. The data suggested that there might be a slight increase of agreement/correlation over time. Both agreement and correlation were in a modest range of approximately 0.5 to 0.6 .

Cronbach's Alphas for the different items are shown in Table 4. Negative values, suggesting that an item was not 
Table 2. Descriptive Statistics (Mean, SD) for EESC Total Scores (Parent- and Patient-Rated), the Two Patient-Rated Satisfaction Scores and ADHD-RS and CGI-S Over Time for All Patients

\begin{tabular}{|lcccccc|}
\hline \multicolumn{1}{|c}{ Mean (SD) } & $\begin{array}{c}\text { EESC Parent } \\
\text { Total Score }\end{array}$ & $\begin{array}{c}\text { EESC Patient } \\
\text { Total Score }\end{array}$ & $\begin{array}{c}\text { EESC Internal } \\
\text { Satisfaction }\end{array}$ & $\begin{array}{c}\text { EESC External } \\
\text { Satisfaction }\end{array}$ & $\begin{array}{c}\text { ADHD-RS } \\
\text { Total Score }\end{array}$ & $\begin{array}{c}\text { CGI-S } \\
\text { ADHD }\end{array}$ \\
\hline \hline Baseline & $77.8(17.45)$ & $74.2(16.89)$ & $13.4(3.53)$ & $9.8(2.53)$ & $32.3(9.64)$ & $4.8(0.87)$ \\
Week 1 & $69.9(17.53)$ & $66.2(16.21)$ & $14.9(3.18)$ & $10.9(2.34)$ & $25.9(10.67)$ & $4.3(0.89)$ \\
Week 2 & $67.1(16.54)$ & $63.3(15.45)$ & $15.3(2.88)$ & $11.2(2.17)$ & $20.9(10.72)$ & $3.8(0.98)$ \\
Week 4 & $64.4(17.73)$ & $60.6(15.43)$ & $15.9(2.75)$ & $11.5(2.17)$ & $17.4(10.11)$ & $3.5(1.07)$ \\
Week 12 & $62.2(17.10)$ & $59.7(15.43)$ & $15.8(2.92)$ & $11.6(2.19)$ & $15.7(9.60)$ & $3.2(1.14)$ \\
Week 24 & $62.0(16.75)$ & $59.5(14.78)$ & $16.0(3.05)$ & $11.6(2.33)$ & $14.4(9.23)$ & $3.1(1.23)$ \\
\hline
\end{tabular}

Abbreviations: $\mathrm{SD}=$ standard deviation.

Table 3. Agreement (Weighted Kappa with 95\% CI) and Correlation (Spearman's Correlation Coefficient with 95\% CI) Between EESC Total Score as Rated by the Parent and the Patient Over Time for All Patients

\begin{tabular}{|lllll|}
\hline & Weighted Kappa Agreement Parent-patient & $\mathbf{9 5 \%}$ CI & Spearman's Correlation Parent-Patient & 95\% CI \\
\hline \hline Baseline & 0.50 & 0.42 to 0.58 & 0.50 & 0.52 \\
Week 1 & 0.54 & 0.46 to 0.62 & 0.54 & 0.43 to 0.57 \\
Week 2 & 0.53 & 0.46 to 0.60 & 0.56 & 0.45 to 0.58 \\
Week 4 & 0.56 & 0.49 to 0.63 & 0.56 & 0.49 to 0.62 \\
Week 12 & 0.57 & 0.49 to 0.64 & 0.61 \\
Week 24 & 0.58 & 0.50 to 0.67 & 0.60 & 0.49 to 0.63 \\
\hline
\end{tabular}

Abbreviations: $\mathrm{CI}=$ confidence interval.

supporting the total score, were found for items 19 ("My child shows a range of emotions") for both parents and patients and for item 24 ("My child is spontaneous") for patients but not for parents. However, most values were in a range that suggests stability of the scale and concordance with the total score, but the values were not that large, that they suggest redundancy. The item-total correlations resembled the results observed using Cronbach's Alpha.

Table 4 contains further information about the agreement and correlation between the previously used parent- and the new patient-rated version. Most values showed a small to moderate correlation and agreement between patients and parents, but items 3 ("My child has sparkle in his/her personality"), 6 ("My child seems easy going"), 14 ("My child's true personality comes through"), and 24 ("My child is spontaneous") showed negligible or no relevant correlation.

Ceiling and floor effects as well as number of missing values are displayed in Table 5. For the total score, ceiling and floor effects were less than $1 \%$ at each time point. The number of observations with missing values, i.e., at least one item missing, is limited with percentages below $5 \%$ at baseline and even lower at the following time points. The number of missing data looking at each specific item did not vary markedly. Mostly, missing data were below $1 \%$ or in the low single-digit percentages. There were no items that did not provide a differential effect in having $90 \%$ of the patients reporting either the lowest or the highest rating.

Table 6 provides the correlations and the agreement between consecutive visits for the EESC total score (both patient and parent perspective) to assess test-retest variability and sensitivity for changes. The correlation and the agreement between consecutive visits of the new patient total score were found to be similar to the parent total scores. Over time, both correlations and agreements were moderate, showing that some change can be detected, but both versions of the scale seem to be stable enough to be reliable.

The correlations between EESC total scores (parent and patient perspective) and ADHD core symptoms as measured by the ADHD-RS total score and subscores, as well as the CGI-S for ADHD, are provided in Table 7. The correlations between the EESC total score and the scales assessing the core symptoms of the disease (ADHD-RS and CGI-S) were small to moderate for both the patient and the parent ratings. The correlations were similar for patients and parents at baseline and after one week (visit 2). At subsequent visits, there was a trend for parent ratings to be more strongly correlated with the core symptom scales rated by the physician. The point estimates of the correlations for inattentive symptoms were always higher than the point estimates for hyperactive/impulsive symptoms as measured on the respective subscores of the ADHD-RS. This was the case both for parent and patient ratings. For parent ratings, confidence intervals for these two correlations were not overlapping or nearly not overlapping from week 1 onwards.

The correlation between the GIPD and the EESC within raters provided in Table 8, e.g., comparing the patient-rated GIPD with patient-rated EESC, was constant over time and always approximately 0.5 . 
Table 4. Minimum and Maximum Internal Consistency (Cronbach's Alpha) for Patient and Parent Ratings, Minimum and Maximum Item-Total Correlation (Spearman's Correlation Coefficient) for Patient and Parent Ratings, Minimum and Maximum Agreement (Weighted Kappa), and Minimum and Maximum Correlation (Spearman's Correlation Coefficient) at the Different Time Points Between EESC Items as Rated by the Parent and the Patient for All Patients

\begin{tabular}{|c|c|c|c|c|c|c|c|c|c|c|c|c|}
\hline \multirow[t]{2}{*}{ Item } & \multicolumn{2}{|c|}{$\begin{array}{l}\text { Cronbach's } \\
\text { Alpha Patient }\end{array}$} & \multicolumn{2}{|c|}{$\begin{array}{l}\text { Cronbach's } \\
\text { Alpha Parent }\end{array}$} & \multicolumn{2}{|c|}{$\begin{array}{c}\text { Item-Total } \\
\text { Correlation Parent }\end{array}$} & \multicolumn{2}{|c|}{$\begin{array}{c}\text { Item-Total } \\
\text { Correlation Patient }\end{array}$} & \multicolumn{2}{|c|}{$\begin{array}{l}\text { Weighted } \\
\text { Kappa }\end{array}$} & \multicolumn{2}{|c|}{$\begin{array}{l}\text { Correlation Between } \\
\text { Parent And Patient }\end{array}$} \\
\hline & Min & $\operatorname{Max}$ & Min & $\operatorname{Max}$ & Min & $\operatorname{Max}$ & Min & $\operatorname{Max}$ & Min & $\operatorname{Max}$ & Min & $\operatorname{Max}$ \\
\hline 1 & 0.29 & 0.36 & 0.37 & 0.48 & 0.38 & 0.52 & 0.38 & 0.45 & 0.18 & 0.34 & 0.22 & 0.37 \\
\hline 2 & 0.46 & 0.52 & 0.52 & 0.66 & 0.57 & 0.67 & 0.53 & 0.61 & 0.15 & 0.30 & 0.18 & $0.28 *$ \\
\hline 3 & 0.41 & 0.57 & 0.41 & 0.57 & 0.48 & 0.62 & 0.48 & 0.63 & 0.07 & 0.24 & 0.06 & $0.27^{*}$ \\
\hline 5 & 0.39 & 0.54 & 0.22 & 0.41 & 0.31 & 0.49 & 0.45 & 0.59 & 0.28 & 0.39 & 0.33 & 0.43 \\
\hline 6 & 0.12 & 0.26 & 0.37 & 0.42 & 0.43 & 0.50 & 0.21 & 0.37 & 0.05 & 0.17 & 0.07 & $0.19^{*}$ \\
\hline 7 & 0.60 & 0.74 & 0.48 & 0.64 & 0.50 & 0.69 & 0.68 & 0.74 & 0.19 & 0.29 & 0.25 & 0.37 \\
\hline 8 & 0.62 & 0.70 & 0.58 & 0.68 & 0.61 & 0.68 & 0.64 & 0.69 & 0.21 & 0.34 & 0.20 & 0.33 \\
\hline 12 & 0.37 & 0.50 & 0.36 & 0.44 & 0.39 & 0.49 & 0.42 & 0.52 & 0.30 & 0.36 & 0.33 & 0.40 \\
\hline 13 & 0.37 & 0.49 & 0.37 & 0.49 & 0.44 & 0.53 & 0.46 & 0.52 & 0.29 & 0.43 & 0.32 & 0.44 \\
\hline 14 & 0.41 & 0.51 & 0.32 & 0.45 & 0.37 & 0.56 & 0.48 & 0.59 & 0.06 & 0.17 & 0.07 & $0.21^{*}$ \\
\hline 15 & 0.38 & 0.50 & 0.47 & 0.58 & 0.54 & 0.61 & 0.42 & 0.55 & 0.21 & 0.36 & 0.23 & 0.31 \\
\hline 16 & 0.47 & 0.59 & 0.34 & 0.50 & 0.43 & 0.54 & 0.52 & 0.64 & 0.15 & 0.33 & 0.17 & 0.35 \\
\hline 17 & 0.56 & 0.63 & 0.59 & 0.64 & 0.58 & 0.67 & 0.63 & 0.69 & 0.15 & 0.27 & 0.15 & $0.26^{*}$ \\
\hline 18 & 0.42 & 0.50 & 0.34 & 0.60 & 0.43 & 0.65 & 0.46 & 0.56 & 0.20 & 0.30 & 0.26 & 0.36 \\
\hline 19 & -0.20 & -0.04 & -0.20 & -0.05 & -0.16 & 0.03 & -0.11 & 0.06 & 0.12 & 0.20 & 0.18 & $0.22 *$ \\
\hline 26 & 0.39 & 0.59 & 0.37 & 0.55 & 0.39 & 0.58 & 0.44 & 0.61 & 0.25 & 0.34 & 0.29 & 0.34 \\
\hline 27 & 0.39 & 0.52 & 0.62 & 0.71 & 0.61 & 0.73 & 0.46 & 0.58 & 0.22 & 0.42 & 0.24 & 0.39 \\
\hline 28 & 0.32 & 0.45 & 0.30 & 0.49 & 0.37 & 0.55 & 0.37 & 0.48 & 0.20 & 0.31 & 0.24 & 0.32 \\
\hline 29 & 0.39 & 0.59 & 0.56 & 0.73 & 0.61 & 0.71 & 0.46 & 0.63 & 0.24 & 0.38 & 0.24 & 0.38 \\
\hline
\end{tabular}

*Does not support the cross informant approach.

\section{DISCUSSION}

The aim of this particular analysis of 6-month data from an ongoing observational ADHD medication study was to evaluate the parent- and the newly devised patient-rated versions of the EESC in an observational setting and to compare it with other scales used in this study.

Some items were translated intuitively correct; however, some items required correction. Item 3 was intensely discussed. It was interpreted differently by the children. However, the result showed good support for the overall aim of the scale. Item 14 was initially perceived differently for children (being happy) vs adolescents (could concentrate well), but also differently to the parent rating.

Overall, the translation was successful. The concept of having children involved in the development of the new version is relevant to the future of construction of new screening tools to be used in the diagnostic process. Only in being able to obtain information from the patient can health professionals fully access the status of the child and the success of the therapy.

The EESC total scores decrease similarly for patients and parents and in parallel over time by about 15 points. Given 
that this is a little less than one standard deviation and that all patients started pharmacotherapy at baseline, it suggests that the new patient-rated EESC version is as sensitive to change as the parent-rated version. This is also supported by the moderate correlation and agreement of measurements at consecutive visits.

Table 5. Floor and Ceiling Effects and Number of Missing Ratings for the EESC Total Score (All Visits) and the Items (Baseline and 6-Month Visit) as Rated by the Parent and the Patient for All Patients

\begin{tabular}{|c|c|c|c|c|}
\hline Item & Visit & Result & Patient & Parent \\
\hline \multirow[t]{24}{*}{ Total score } & \multirow[t]{4}{*}{ Baseline } & Minimum & $1(0.2 \%)$ & $1(0.2 \%)$ \\
\hline & & $>\operatorname{Min}<\operatorname{Max}$ & $462(94.9 \%)$ & $462(94.7 \%)$ \\
\hline & & Maximum & $1(0.2 \%)$ & $1(0.2 \%)$ \\
\hline & & Nmiss & $23(4.7 \%)$ & $24(4.9 \%)$ \\
\hline & \multirow[t]{4}{*}{ Week 1} & Minimum & $1(0.2 \%)$ & $1(0.2 \%)$ \\
\hline & & $>\operatorname{Min}<\operatorname{Max}$ & 424 (96.4\%) & $423(96.4 \%)$ \\
\hline & & Maximum & $1(0.2 \%)$ & $2(0.5 \%)$ \\
\hline & & Nmiss & $14(3.2 \%)$ & $13(3.0 \%)$ \\
\hline & \multirow[t]{4}{*}{ Week 2} & Minimum & $1(0.2 \%)$ & $1(0.2 \%)$ \\
\hline & & $>\operatorname{Min}<\operatorname{Max}$ & $421(97.5 \%)$ & 414 (95.8\%) \\
\hline & & Maximum & $1(0.2 \%)$ & $1(0.2 \%)$ \\
\hline & & Nmiss & $9(2.1 \%)$ & $16(3.7 \%)$ \\
\hline & \multirow[t]{4}{*}{ Week 4} & Minimum & $1(0.2 \%)$ & $2(0.4 \%)$ \\
\hline & & $>\operatorname{Min}<\operatorname{Max}$ & $436(97.5 \%)$ & $435(97.1 \%)$ \\
\hline & & Maximum & $1(0.2 \%)$ & $1(0.2 \%)$ \\
\hline & & Nmiss & $9(2.0 \%)$ & $10(2.2 \%)$ \\
\hline & \multirow[t]{4}{*}{ Week 12} & Minimum & $1(0.2 \%)$ & $1(0.2 \%)$ \\
\hline & & $>\operatorname{Min}<\operatorname{Max}$ & 409 (96.2\%) & $413(97.2 \%)$ \\
\hline & & Maximum & $1(0.2 \%)$ & $1(0.2 \%)$ \\
\hline & & Nmiss & $14(3.3 \%)$ & $10(2.4 \%)$ \\
\hline & \multirow[t]{4}{*}{ Week 24} & Minimum & $1(0.3 \%)$ & $1(0.3 \%)$ \\
\hline & & $>\operatorname{Min}<\operatorname{Max}$ & $384(99.0 \%)$ & $386(99.5 \%)$ \\
\hline & & Maximum & $1(0.3 \%)$ & $1(0.3 \%)$ \\
\hline & & Nmiss & $2(0.5 \%)$ & $0(0.0 \%)$ \\
\hline \multirow[t]{8}{*}{1} & \multirow[t]{4}{*}{ Baseline } & 1 & $270(55.4 \%)$ & $287(58.8 \%)$ \\
\hline & & $2-4$ & $194(39.8 \%)$ & $184(37.7 \%)$ \\
\hline & & 5 & $20(4.1 \%)$ & $16(3.3 \%)$ \\
\hline & & Nmiss & $3(0.6 \%)$ & $1(0.2 \%)$ \\
\hline & \multirow[t]{4}{*}{6 Months } & 1 & $251(64.0 \%)$ & $272(69.4 \%)$ \\
\hline & & $2-4$ & $132(33.7 \%)$ & $116(29.6 \%)$ \\
\hline & & 5 & $8(2.0 \%)$ & $2(0.5 \%)$ \\
\hline & & Nmiss & $1(0.3 \%)$ & $2(0.5 \%)$ \\
\hline \multirow[t]{8}{*}{2} & \multirow[t]{4}{*}{ Baseline } & 1 & $154(31.6 \%)$ & $173(35.5 \%)$ \\
\hline & & $2-4$ & $295(60.6 \%)$ & $290(59.4 \%)$ \\
\hline & & 5 & $35(7.2 \%)$ & $17(3.5 \%)$ \\
\hline & & Nmiss & $3(0.6 \%)$ & $8(1.6 \%)$ \\
\hline & \multirow[t]{4}{*}{6 Months } & 1 & $222(56.6 \%)$ & $240(61.2 \%)$ \\
\hline & & $2-4$ & $155(39.5 \%)$ & $143(36.5 \%)$ \\
\hline & & 5 & $12(3.1 \%)$ & $5(1.3 \%)$ \\
\hline & & Nmiss & $3(0.8 \%)$ & $4(1.0 \%)$ \\
\hline
\end{tabular}

(Table 5) contd...

\begin{tabular}{|c|c|c|c|c|}
\hline Item & Visit & Result & Patient & Parent \\
\hline \multirow[t]{8}{*}{3} & Baseline & 1 & 44 (9.0\%) & $111(22.7 \%)$ \\
\hline & & $2-4$ & $326(66.9 \%)$ & 347 (71.1\%) \\
\hline & & 5 & $103(21.1 \%)$ & $21(4.3 \%)$ \\
\hline & & Nmiss & $14(2.9 \%)$ & $9(1.8 \%)$ \\
\hline & 6 Months & 1 & $79(20.2 \%)$ & $121(30.9 \%)$ \\
\hline & & $2-4$ & $280(71.4 \%)$ & $250(63.8 \%)$ \\
\hline & & 5 & $30(7.7 \%)$ & $21(5.4 \%)$ \\
\hline & & Nmiss & $3(0.8 \%)$ & $0(0.0 \%)$ \\
\hline \multirow[t]{8}{*}{4} & Baseline & 1 & $78(16.0 \%)$ & $28(5.7 \%)$ \\
\hline & & $2-4$ & $350(71.9 \%)$ & $418(85.7 \%)$ \\
\hline & & 5 & $55(11.3 \%)$ & $39(8.0 \%)$ \\
\hline & & Nmiss & $4(0.8 \%)$ & $3(0.6 \%)$ \\
\hline & 6 Months & 1 & $133(33.9 \%)$ & $76(19.4 \%)$ \\
\hline & & $2-4$ & $248(63.3 \%)$ & $307(78.3 \%)$ \\
\hline & & 5 & $10(2.6 \%)$ & $9(2.3 \%)$ \\
\hline & & Nmiss & $1(0.3 \%)$ & $0(0.0 \%)$ \\
\hline \multirow[t]{8}{*}{5} & Baseline & 1 & $60(12.3 \%)$ & $19(3.9 \%)$ \\
\hline & & $2-4$ & $298(61.2 \%)$ & $268(54.9 \%)$ \\
\hline & & 5 & $126(25.9 \%)$ & $199(40.8 \%)$ \\
\hline & & Nmiss & $3(0.6 \%)$ & $2(0.4 \%)$ \\
\hline & 6 Months & 1 & $96(24.5 \%)$ & $41(10.5 \%)$ \\
\hline & & $2-4$ & $270(68.9 \%)$ & $296(75.5 \%)$ \\
\hline & & 5 & $25(6.4 \%)$ & $55(14.0 \%)$ \\
\hline & & Nmiss & $1(0.3 \%)$ & $0(0.0 \%)$ \\
\hline \multirow[t]{8}{*}{6} & Baseline & 1 & $84(17.2 \%)$ & $46(9.4 \%)$ \\
\hline & & $2-4$ & $307(63.0 \%)$ & $381(78.1 \%)$ \\
\hline & & 5 & $91(18.7 \%)$ & $56(11.5 \%)$ \\
\hline & & Nmiss & $5(1.0 \%)$ & $5(1.0 \%)$ \\
\hline & 6 Months & 1 & $78(19.9 \%)$ & $50(12.8 \%)$ \\
\hline & & $2-4$ & $252(64.3 \%)$ & $318(81.1 \%)$ \\
\hline & & 5 & $61(15.6 \%)$ & $22(5.6 \%)$ \\
\hline & & Nmiss & $1(0.3 \%)$ & $2(0.5 \%)$ \\
\hline \multirow[t]{8}{*}{7} & Baseline & 1 & $143(29.4 \%)$ & $24(4.9 \%)$ \\
\hline & & $2-4$ & $304(62.4 \%)$ & $357(73.2 \%)$ \\
\hline & & 5 & $36(7.4 \%)$ & $98(20.1 \%)$ \\
\hline & & Nmiss & $4(0.8 \%)$ & $9(1.8 \%)$ \\
\hline & 6 Months & 1 & $173(44.1 \%)$ & $65(16.6 \%)$ \\
\hline & & $2-4$ & $209(53.3 \%)$ & $301(76.8 \%)$ \\
\hline & & 5 & $9(2.3 \%)$ & $25(6.4 \%)$ \\
\hline & & Nmiss & $1(0.3 \%)$ & $1(0.3 \%)$ \\
\hline \multirow[t]{8}{*}{8} & Baseline & 1 & $183(37.6 \%)$ & $141(28.9 \%)$ \\
\hline & & $2-4$ & $274(56.3 \%)$ & $312(63.9 \%)$ \\
\hline & & 5 & $24(4.9 \%)$ & $29(5.9 \%)$ \\
\hline & & Nmiss & $6(1.2 \%)$ & $6(1.2 \%)$ \\
\hline & 6 Months & 1 & $217(55.4 \%)$ & $215(54.8 \%)$ \\
\hline & & $2-4$ & $167(42.6 \%)$ & $176(44.9 \%)$ \\
\hline & & 5 & $5(1.3 \%)$ & $1(0.3 \%)$ \\
\hline & & Nmiss & $3(0.8 \%)$ & $0(0.0 \%)$ \\
\hline \multirow[t]{8}{*}{9} & Baseline & 1 & $245(50.3 \%)$ & $170(34.8 \%)$ \\
\hline & & $2-4$ & $207(42.5 \%)$ & $283(58.0 \%)$ \\
\hline & & 5 & $32(6.6 \%)$ & $34(7.0 \%)$ \\
\hline & & Nmiss & $3(0.6 \%)$ & $1(0.2 \%)$ \\
\hline & 6 Months & 1 & $191(48.7 \%)$ & $141(36.0 \%)$ \\
\hline & & $2-4$ & $196(50.0 \%)$ & $246(62.8 \%)$ \\
\hline & & 5 & $4(1.0 \%)$ & $5(1.3 \%)$ \\
\hline & & Nmiss & $1(0.3 \%)$ & $0(0.0 \%)$ \\
\hline
\end{tabular}




\begin{tabular}{|c|c|c|c|c|}
\hline Item & Visit & Result & Patient & Parent \\
\hline \multirow[t]{8}{*}{10} & Baseline & 1 & $161(33.1 \%)$ & $124(25.4 \%)$ \\
\hline & & $2-4$ & $293(60.2 \%)$ & $321(65.8 \%)$ \\
\hline & & 5 & $30(6.2 \%)$ & $42(8.6 \%)$ \\
\hline & & Nmiss & $3(0.6 \%)$ & $1(0.2 \%)$ \\
\hline & 6 Months & 1 & $191(48.7 \%)$ & $196(50.0 \%)$ \\
\hline & & $2-4$ & $191(48.7 \%)$ & $191(48.7 \%)$ \\
\hline & & 5 & $9(2.3 \%)$ & $4(1.0 \%)$ \\
\hline & & Nmiss & $1(0.3 \%)$ & $1(0.3 \%)$ \\
\hline \multirow[t]{8}{*}{11} & Baseline & 1 & $173(35.5 \%)$ & $170(34.8 \%)$ \\
\hline & & $2-4$ & $268(55.0 \%)$ & $270(55.3 \%)$ \\
\hline & & 5 & $36(7.4 \%)$ & $42(8.6 \%)$ \\
\hline & & Nmiss & $10(2.1 \%)$ & $6(1.2 \%)$ \\
\hline & 6 Months & 1 & $230(58.7 \%)$ & $278(70.9 \%)$ \\
\hline & & $2-4$ & $151(38.5 \%)$ & $110(28.1 \%)$ \\
\hline & & 5 & $10(2.6 \%)$ & $4(1.0 \%)$ \\
\hline & & Nmiss & $1(0.3 \%)$ & $0(0.0 \%)$ \\
\hline \multirow[t]{8}{*}{12} & Baseline & 1 & $242(49.7 \%)$ & $128(26.2 \%)$ \\
\hline & & $2-4$ & $199(40.9 \%)$ & $313(64.1 \%)$ \\
\hline & & 5 & $43(8.8 \%)$ & $46(9.4 \%)$ \\
\hline & & Nmiss & $3(0.6 \%)$ & $1(0.2 \%)$ \\
\hline & 6 Months & 1 & $219(55.9 \%)$ & $93(23.7 \%)$ \\
\hline & & $2-4$ & $160(40.8 \%)$ & $283(72.2 \%)$ \\
\hline & & 5 & $12(3.1 \%)$ & $16(4.1 \%)$ \\
\hline & & Nmiss & $1(0.3 \%)$ & $0(0.0 \%)$ \\
\hline \multirow[t]{8}{*}{13} & Baseline & 1 & $237(48.7 \%)$ & $157(32.2 \%)$ \\
\hline & & $2-4$ & $222(45.6 \%)$ & $282(57.8 \%)$ \\
\hline & & 5 & $24(4.9 \%)$ & $46(9.4 \%)$ \\
\hline & & Nmiss & $4(0.8 \%)$ & $3(0.6 \%)$ \\
\hline & 6 Months & 1 & $273(69.6 \%)$ & $192(49.0 \%)$ \\
\hline & & $2-4$ & $113(28.8 \%)$ & $185(47.2 \%)$ \\
\hline & & 5 & $5(.3 \%)$ & $14(3.6 \%)$ \\
\hline & & Nmiss & $1(0.3 \%)$ & $1(0.3 \%)$ \\
\hline \multirow[t]{8}{*}{14} & Baseline & 1 & $43(8.8 \%)$ & $37(7.6 \%)$ \\
\hline & & $2-4$ & $353(72.5 \%)$ & $339(69.5 \%)$ \\
\hline & & 5 & $87(17.9 \%)$ & $85(17.4 \%)$ \\
\hline & & Nmiss & $4(0.8 \%)$ & $27(5.5 \%)$ \\
\hline & 6 Months & 1 & $98(25.0 \%)$ & $64(16.3 \%)$ \\
\hline & & $2-4$ & $273(69.6 \%)$ & $275(70.2 \%)$ \\
\hline & & 5 & $19(4.8 \%)$ & $49(12.5 \%)$ \\
\hline & & Nmiss & $2(0.5 \%)$ & $4(1.0 \%)$ \\
\hline \multirow[t]{8}{*}{15} & Baseline & 1 & $199(40.9 \%)$ & $195(40.0 \%)$ \\
\hline & & $2-4$ & $260(53.4 \%)$ & $249(51.0 \%)$ \\
\hline & & 5 & $25(5.1 \%)$ & $39(8.0 \%)$ \\
\hline & & Nmiss & $3(0.6 \%)$ & $5(1.0 \%)$ \\
\hline & 6 Months & 1 & $216(55.1 \%)$ & $219(55.9 \%)$ \\
\hline & & $2-4$ & $166(42.3 \%)$ & $167(42.6 \%)$ \\
\hline & & 5 & $10(2.6 \%)$ & $6(1.5 \%)$ \\
\hline & & Nmiss & $0(0.0 \%)$ & $0(0.0 \%)$ \\
\hline \multirow[t]{8}{*}{16} & Baseline & 1 & $90(18.5 \%)$ & $42(8.6 \%)$ \\
\hline & & $2-4$ & $330(67.8 \%)$ & $332(68.0 \%)$ \\
\hline & & 5 & $59(12.1 \%)$ & $113(23.2 \%)$ \\
\hline & & Nmiss & $8(1.6 \%)$ & $1(0.2 \%)$ \\
\hline & 6 Months & 1 & $153(39.0 \%)$ & $99(25.3 \%)$ \\
\hline & & $2-4$ & $228(58.2 \%)$ & $282(71.9 \%)$ \\
\hline & & 5 & $8(2.0 \%)$ & $11(2.8 \%)$ \\
\hline & & Nmiss & $3(0.8 \%)$ & $0(0.0 \%)$ \\
\hline
\end{tabular}

\begin{tabular}{|c|c|c|c|c|}
\hline Item & Visit & Result & Patient & Parent \\
\hline \multirow[t]{8}{*}{17} & Baseline & 1 & $128(26.3 \%)$ & $223(45.7 \%)$ \\
\hline & & $2-4$ & $294(60.4 \%)$ & $235(48.2 \%)$ \\
\hline & & 5 & $51(10.5 \%)$ & $25(5.1 \%)$ \\
\hline & & Nmiss & $14(2.9 \%)$ & $5(1.0 \%)$ \\
\hline & 6 Months & 1 & $172(43.9 \%)$ & $223(56.9 \%)$ \\
\hline & & $2-4$ & $198(50.5 \%)$ & $165(42.1 \%)$ \\
\hline & & 5 & $17(4.3 \%)$ & $3(0.8 \%)$ \\
\hline & & Nmiss & $5(1.3 \%)$ & $1(0.3 \%)$ \\
\hline \multirow[t]{8}{*}{18} & Baseline & 1 & $183(37.6 \%)$ & $31(6.4 \%)$ \\
\hline & & $2-4$ & $242(49.7 \%)$ & $272(55.7 \%)$ \\
\hline & & 5 & $59(12.1 \%)$ & $182(37.3 \%)$ \\
\hline & & Nmiss & $3(0.6 \%)$ & $3(0.6 \%)$ \\
\hline & 6 Months & 1 & $173(44.1 \%)$ & $65(16.6 \%)$ \\
\hline & & $2-4$ & $207(52.8 \%)$ & $287(73.2 \%)$ \\
\hline & & 5 & $12(3.1 \%)$ & $39(9.9 \%)$ \\
\hline & & Nmiss & $0(0.0 \%)$ & $1(0.3 \%)$ \\
\hline \multirow[t]{8}{*}{19} & Baseline & 1 & $88(18.1 \%)$ & $121(24.8 \%)$ \\
\hline & & $2-4$ & $319(65.5 \%)$ & $344(70.5 \%)$ \\
\hline & & 5 & $70(14.4 \%)$ & $19(3.9 \%)$ \\
\hline & & Nmiss & $10(2.1 \%)$ & $4(0.8 \%)$ \\
\hline & 6 Months & 1 & $52(13.3 \%)$ & $57(14.5 \%)$ \\
\hline & & $2-4$ & $268(68.4 \%)$ & $311(79.3 \%)$ \\
\hline & & 5 & $70(17.9 \%)$ & $23(5.9 \%)$ \\
\hline & & Nmiss & $2(0.5 \%)$ & $1(0.3 \%)$ \\
\hline \multirow[t]{8}{*}{20} & Baseline & 1 & $139(28.5 \%)$ & $62(12.7 \%)$ \\
\hline & & $2-4$ & $297(61.0 \%)$ & $387(79.3 \%)$ \\
\hline & & 5 & $41(8.4 \%)$ & $36(7.4 \%)$ \\
\hline & & Nmiss & $10(2.1 \%)$ & $3(0.6 \%)$ \\
\hline & 6 Months & 1 & $162(41.3 \%)$ & $90(23.0 \%)$ \\
\hline & & $2-4$ & $216(55.1 \%)$ & $294(75.0 \%)$ \\
\hline & & 5 & $13(3.3 \%)$ & $6(1.5 \%)$ \\
\hline & & Nmiss & $1(0.3 \%)$ & $2(0.5 \%)$ \\
\hline \multirow[t]{8}{*}{21} & Baseline & 1 & $97(19.9 \%)$ & $164(33.6 \%)$ \\
\hline & & $2-4$ & $364(74.7 \%)$ & $318(65.2 \%)$ \\
\hline & & 5 & $22(4.5 \%)$ & $5(1.0 \%)$ \\
\hline & & Nmiss & $4(0.8 \%)$ & $1(0.2 \%)$ \\
\hline & 6 Months & 1 & $139(35.5 \%)$ & $157(40.1 \%)$ \\
\hline & & $2-4$ & $250(63.8 \%)$ & $230(58.7 \%)$ \\
\hline & & 5 & $2(0.5 \%)$ & $2(0.5 \%)$ \\
\hline & & Nmiss & $1(0.3 \%)$ & $3(0.8 \%)$ \\
\hline \multirow[t]{8}{*}{22} & Baseline & 1 & $146(30.0 \%)$ & $175(35.9 \%)$ \\
\hline & & $2-4$ & $302(62.0 \%)$ & $290(59.4 \%)$ \\
\hline & & 5 & $35(7.2 \%)$ & $12(2.5 \%)$ \\
\hline & & Nmiss & $4(0.8 \%)$ & $11(2.3 \%)$ \\
\hline & 6 Months & 1 & $173(44.1 \%)$ & $231(58.9 \%)$ \\
\hline & & $2-4$ & $207(52.8 \%)$ & $157(40.1 \%)$ \\
\hline & & 5 & $9(2.3 \%)$ & $1(0.3 \%)$ \\
\hline & & Nmiss & $3(0.8 \%)$ & $3(0.8 \%)$ \\
\hline \multirow[t]{8}{*}{23} & Baseline & 1 & $134(27.5 \%)$ & $43(8.8 \%)$ \\
\hline & & $2-4$ & $275(56.5 \%)$ & $287(58.8 \%)$ \\
\hline & & 5 & $75(15.4 \%)$ & $156(32.0 \%)$ \\
\hline & & Nmiss & $3(0.6 \%)$ & $2(0.4 \%)$ \\
\hline & 6 Months & 1 & $136(34.7 \%)$ & $67(17.1 \%)$ \\
\hline & & $2-4$ & $231(58.9 \%)$ & $299(76.3 \%)$ \\
\hline & & 5 & $23(5.9 \%)$ & $25(6.4 \%)$ \\
\hline & & Nmiss & $2(0.5 \%)$ & $1(0.3 \%)$ \\
\hline
\end{tabular}




\begin{tabular}{|c|c|c|c|c|}
\hline Item & Visit & Result & Patient & Parent \\
\hline \multirow[t]{8}{*}{24} & Baseline & 1 & $103(21.1 \%)$ & $151(30.9 \%)$ \\
\hline & & $2-4$ & $316(64.9 \%)$ & $319(65.4 \%)$ \\
\hline & & 5 & $63(12.9 \%)$ & $16(3.3 \%)$ \\
\hline & & Nmiss & $5(1.0 \%)$ & $2(0.4 \%)$ \\
\hline & 6 Months & 1 & $41(10.5 \%)$ & $110(28.1 \%)$ \\
\hline & & $2-4$ & $264(67.3 \%)$ & $268(68.4 \%)$ \\
\hline & & 5 & $86(21.9 \%)$ & $12(3.1 \%)$ \\
\hline & & Nmiss & $1(0.3 \%)$ & $2(0.5 \%)$ \\
\hline \multirow[t]{8}{*}{25} & Baseline & 1 & $130(26.7 \%)$ & $46(9.4 \%)$ \\
\hline & & $2-4$ & $265(54.4 \%)$ & $324(66.4 \%)$ \\
\hline & & 5 & $86(17.7 \%)$ & $117(24.0 \%)$ \\
\hline & & Nmiss & $6(1.2 \%)$ & $1(0.2 \%)$ \\
\hline & 6 Months & 1 & $142(36.2 \%)$ & $76(19.4 \%)$ \\
\hline & & $2-4$ & $228(58.2 \%)$ & $285(72.7 \%)$ \\
\hline & & 5 & $18(4.6 \%)$ & $30(7.7 \%)$ \\
\hline & & Nmiss & $4(1.0 \%)$ & $1(0.3 \%)$ \\
\hline \multirow[t]{8}{*}{26} & Baseline & 1 & $95(19.5 \%)$ & $164(33.6 \%)$ \\
\hline & & $2-4$ & $368(75.6 \%)$ & $316(64.8 \%)$ \\
\hline & & 5 & $19(3.9 \%)$ & $7(1.4 \%)$ \\
\hline & & Nmiss & $5(1.0 \%)$ & $1(0.2 \%)$ \\
\hline & 6 Months & 1 & $122(31.1 \%)$ & $157(40.1 \%)$ \\
\hline & & $2-4$ & $265(67.6 \%)$ & $232(59.2 \%)$ \\
\hline & & 5 & $4(1.0 \%)$ & $2(0.5 \%)$ \\
\hline & & Nmiss & $1(0.3 \%)$ & $1(0.3 \%)$ \\
\hline \multirow[t]{8}{*}{27} & Baseline & 1 & $185(38.0 \%)$ & $138(28.3 \%)$ \\
\hline & & $2-4$ & $265(54.4 \%)$ & $332(68.0 \%)$ \\
\hline & & 5 & $32(6.6 \%)$ & $16(3.3 \%)$ \\
\hline & & Nmiss & $5(1.0 \%)$ & $2(0.4 \%)$ \\
\hline & 6 Months & 1 & $187(47.7 \%)$ & $140(35.7 \%)$ \\
\hline & & $2-4$ & $194(49.5 \%)$ & $247(63.0 \%)$ \\
\hline & & 5 & $9(2.3 \%)$ & $4(1.0 \%)$ \\
\hline & & Nmiss & $2(0.5 \%)$ & $1(0.3 \%)$ \\
\hline \multirow[t]{8}{*}{28} & Baseline & 1 & $125(25.7 \%)$ & $145(29.7 \%)$ \\
\hline & & $2-4$ & $318(65.3 \%)$ & $316(64.8 \%)$ \\
\hline & & 5 & $39(8.0 \%)$ & $26(5.3 \%)$ \\
\hline & & Nmiss & $5(1.0 \%)$ & $1(0.2 \%)$ \\
\hline & 6 Months & 1 & $125(31.9 \%)$ & $145(37.0 \%)$ \\
\hline & & $2-4$ & $248(63.3 \%)$ & $235(59.9 \%)$ \\
\hline & & 5 & $16(4.1 \%)$ & $11(2.8 \%)$ \\
\hline & & Nmiss & $3(0.8 \%)$ & $1(0.3 \%)$ \\
\hline \multirow[t]{8}{*}{29} & Baseline & 1 & $117(24.0 \%)$ & $52(10.7 \%)$ \\
\hline & & $2-4$ & $314(64.5 \%)$ & $398(81.6 \%)$ \\
\hline & & 5 & $43(8.8 \%)$ & $35(7.2 \%)$ \\
\hline & & Nmiss & $13(2.7 \%)$ & $3(0.6 \%)$ \\
\hline & 6 Months & 1 & $150(38.3 \%)$ & $103(26.3 \%)$ \\
\hline & & $2-4$ & $226(57.7 \%)$ & $277(70.7 \%)$ \\
\hline & & 5 & $15(3.8 \%)$ & $11(2.8 \%)$ \\
\hline & & Nmiss & $1(0.3 \%)$ & $1(0.3 \%)$ \\
\hline
\end{tabular}

Abbreviations: Nmiss=missing data.

Interestingly, the new patient-rated total score was always about 3 to 4 points lower than the parent-rated score. This difference in patient and parent ratings was also found for the GIPD [41]. One can only speculate about the reason for such differences. Either the severity of the disorder is less perceived by the patients compared to the parents, or the understanding of the items is different. In the case of the EESC, the latter might be supported by the negligible correlation of the patient and parent rating of the EESC items 3 ("My child has sparkle in his/her personality"), 6 ("My child seems easy going"), 14 ("My child's true personality comes through"), and 24 ("My child is spontaneous") for patients.

Ceiling and floor effects as well as the amount of missing items were quite limited. This supports that the scale can be easily applied and that it is possible to detect differences between patients at the upper and lower end of emotional expression. In addition, item-total correlations and analysis of Cronbach's Alpha showed mostly good support of the different items for the total scores. Only the items 19 ("My child shows a range of emotions") for both parents and patients and for item 24 ("My child is spontaneous") for patients might have been misunderstood by raters.

The correlation between raters within EESC was of similar size compared to correlation within raters comparing EESC and GIPD, i.e., approximately 0.5 . These correlations between EESC and GIPD were generally higher than between EESC and scales measuring core symptoms (ADHD-RS/CGI-S) - especially for hyperactivity/impulsivity. Earlier studies on the correlations between the ratings of behavioral and emotional problems as rated by parents and children or adolescents also reveal little agreement in the ratings of parents and their children. For example, Achenbach et al., found in their meta-analysis a correlation of $r=0.25$ between parents and children ratings of behavioral and emotional problems [43]. This result was replicated in a German sample [44]. This supports that Emotional Expression is a concept beyond core symptoms of ADHD. The more general questions of the GIPD might capture some of this concept more than the very specific questions of the ADHD-RS. Furthermore, the additional perspective of the patient complements the clinical perspective as well as the information provided by the parent.

Of special interest in this regard is the observation that the point estimates of the correlations for inattentive symptoms were always higher than the point estimates for hyperactive/impulsive symptoms as measured on the respective subscores of the ADHD-RS and also always higher (except for the patient-rating at baseline) for the CGI$\mathrm{S}$. This was the case both for parent and patient ratings. It might be either that some items of the EESC reflect or are misinterpreted as inattention like "My child does not talk enough", "My child zones out", or "My child's emotions seem flat". Or the latent concept of inattention is more closely related to the concept of emotional expression than hyperactivity and impulsivity. As the CGI-S measures both the inattentive symptoms as well as the hyperactive/impulsive symptoms, correlations were mostly between those for the two subscores of the ADHD-RS.

However, over time there was a trend for the parent-rated EESC to be more strongly correlated with the core symptoms scales than the new patient-rated EESC. A similar 
Table 6. Correlation (Spearman's Correlation Coefficient with 95\% CI) and Agreement (Weighted Kappa with 95\% CI) Between Consecutively Visits for the EESC Total Score to Assess Test-Retest Variability and Sensitivity for Changes as Rated by the Parent and the Patient for All Patients

\begin{tabular}{|c|c|c|c|c|}
\hline & Parent & & Patient & \\
\hline Baseline $v s$ Week 1 & 0.54 & 0.45 to 0.62 & 0.48 & 0.39 to 0.56 \\
\hline Week 1 vs Week 2 & 0.58 & 0.50 to 0.65 & 0.62 & 0.54 to 0.68 \\
\hline Week $2 v s$ Week 4 & 0.67 & 0.60 to 0.72 & 0.64 & 0.56 to 0.70 \\
\hline Week 4 vs Week 12 & 0.64 & 0.57 to 0.70 & 0.55 & 0.47 to 0.63 \\
\hline Week $12 v s$ Week 24 & Weighted Kappa & $95 \%$ CI & Weighted Kappa & $95 \%$ CI \\
\hline Baseline $v s$ Week 1 & 0.52 & 0.42 to 0.61 & 0.45 & 0.35 to 0.54 \\
\hline Week 1 vs Week 2 & 0.59 & 0.49 to 0.70 & 0.58 & 0.49 to 0.66 \\
\hline Week 2 vs Week 4 & 0.65 & 0.56 to 0.74 & 0.58 & 0.49 to 0.67 \\
\hline
\end{tabular}

Table 7. Correlation (Spearman's Correlation Coefficient $\mathbf{r}$ with 95\% Confidence Interval Between EESC Total Score as Rated by the Parent and the Patient, and ADHD Symptoms as Measured by the ADHD-RS Total Score, Hyperactivity/Impulsivity Subscore, Inattention Subscore, and the CGI-S for ADHD Over Time for All Patients

\begin{tabular}{|c|c|c|c|c|c|c|c|}
\hline \multirow[t]{2}{*}{ Visit } & \multirow[t]{2}{*}{ Score } & \multicolumn{3}{|c|}{ Patient } & \multicolumn{3}{|c|}{ Parent } \\
\hline & & $\mathbf{r}$ & $95 \% \mathrm{LL}$ & $95 \%$ UL & $\mathbf{r}$ & $95 \%$ LL & $95 \%$ UL \\
\hline \multirow[t]{4}{*}{ Visit 1} & ADHD Total & 0.12 & 0.03 & 0.21 & 0.10 & 0.01 & 0.19 \\
\hline & Hyperactivity subscore & 0.06 & -0.03 & 0.15 & -0.02 & -0.11 & 0.07 \\
\hline & Inattention subscore & 0.16 & 0.07 & 0.25 & 0.25 & 0.16 & 0.33 \\
\hline & CGI-S & 0.18 & 0.09 & 0.26 & 0.10 & 0.01 & 0.19 \\
\hline \multirow[t]{4}{*}{ Visit 2} & ADHD Total & 0.21 & 0.11 & 0.30 & 0.29 & 0.20 & 0.38 \\
\hline & Hyperactivity subscore & 0.13 & 0.03 & 0.22 & 0.18 & 0.09 & 0.27 \\
\hline & Inattention subscore & 0.23 & 0.14 & 0.32 & 0.34 & 0.25 & 0.42 \\
\hline & CGI-S & 0.22 & 0.13 & 0.31 & 0.20 & 0.11 & 0.29 \\
\hline \multirow[t]{4}{*}{ Visit 3} & ADHD Total & 0.17 & 0.08 & 0.26 & 0.36 & 0.27 & 0.44 \\
\hline & Hyperactivity subscore & 0.07 & -0.03 & 0.16 & 0.20 & 0.11 & 0.30 \\
\hline & Inattention subscore & 0.23 & 0.14 & 0.32 & 0.42 & 0.34 & 0.50 \\
\hline & CGI-S & 0.17 & 0.08 & 0.26 & 0.22 & 0.13 & 0.31 \\
\hline \multirow[t]{4}{*}{ Visit 4} & ADHD Total & 0.29 & 0.20 & 0.37 & 0.38 & 0.29 & 0.46 \\
\hline & Hyperactivity subscore & 0.17 & 0.08 & 0.26 & 0.20 & 0.10 & 0.28 \\
\hline & Inattention subscore & 0.32 & 0.23 & 0.40 & 0.45 & 0.37 & 0.52 \\
\hline & CGI-S & 0.24 & 0.15 & 0.33 & 0.32 & 0.24 & 0.40 \\
\hline \multirow[t]{4}{*}{ Visit 5} & ADHD Total & 0.26 & 0.17 & 0.35 & 0.33 & 0.24 & 0.42 \\
\hline & Hyperactivity subscore & 0.14 & 0.05 & 0.24 & 0.16 & 0.07 & 0.25 \\
\hline & Inattention subscore & 0.30 & 0.21 & 0.39 & 0.40 & 0.32 & 0.48 \\
\hline & CGI-S & 0.26 & 0.16 & 0.34 & 0.30 & 0.21 & 0.38 \\
\hline \multirow[t]{4}{*}{ Visit 6} & ADHD Total & 0.30 & 0.20 & 0.39 & 0.43 & 0.35 & 0.51 \\
\hline & Hyperactivity subscore & 0.20 & 0.11 & 0.30 & 0.30 & 0.20 & 0.39 \\
\hline & Inattention subscore & 0.33 & 0.24 & 0.42 & 0.47 & 0.39 & 0.55 \\
\hline & CGI-S & 0.17 & 0.07 & 0.27 & 0.28 & 0.19 & 0.37 \\
\hline
\end{tabular}


Table 8. Correlation (Spearman's Correlation Coefficient $\mathbf{r}$ with 95\% Confidence Interval Between EESC Total Score and GIPD Total Score within Rater, i.e., Parent EESC vs Parent GIPD and Patient EESC vs Patient GIPD Ratings, Over Time for All Patients

\begin{tabular}{|ccccc|}
\hline Visit & Rater & $\mathbf{r}$ & Lower Limit & Upper Limit \\
\hline \hline Baseline & Patient & 0.58 & 0.52 & 0.64 \\
& Parent & 0.40 & 0.32 & 0.47 \\
Week 1 & Patient & 0.52 & 0.45 & 0.59 \\
& Parent & 0.46 & 0.38 & 0.53 \\
Week 2 & Patient & 0.50 & 0.42 & 0.57 \\
& Parent & 0.45 & 0.37 & 0.52 \\
Week 4 & Patient & 0.51 & 0.44 & 0.58 \\
& Parent & 0.44 & 0.36 & 0.51 \\
Week 12 & Patient & 0.49 & 0.42 & 0.56 \\
& Parent & 0.47 & 0.39 & 0.54 \\
Week 24 & Patient & 0.51 & 0.44 & 0.58 \\
& Parent & 0.51 & 0.43 & 0.58 \\
\hline
\end{tabular}

finding was observed for the patient and parent perspectives of the GIPD in two clinical open-label trials in Germany [41]. Wehmeier et al., argue that the higher correlation between parent and physician perspectives may be due to the fact that the physicians based their ratings primarily on the information from the parents rather than the patients. A continued improvement of the relationship between parents and physicians might thus explain an increase of the correlations between their ratings observed in this study. The smaller correlation for the patient-rated version of the EESC underscores that this new scale contains more additional information than the parent-rated version.

\section{CONCLUSIONS}

In summary, this analysis showed that both the parentand the patient-rated version of the EESC are tools that can be used in routine settings in addition to clinical study centres. Both versions of the EESC have sound psychometric properties. Finally, the newly devised patient-rated version of the EESC provides additional insight and further investigation of the patient-rated scale might be beneficial. It might be possible to detect differences between treatment options in terms of this patient-assessed emotional expression.

\section{COMPETING INTERESTS}

Research was funded by Lilly Deutschland $\mathrm{GmbH}$, Bad Homburg, Germany. Alexander Schacht is and Peter Wehmeier was employee of Lilly Deutschland GmbH.

Alexander Schacht is stockholder of Eli Lilly.

Michael Huss is member of Eli Lilly advisory board and has received an unrestricted fund by Eli Lilly.

\section{AUTHOR CONTRIBUTION}

Alexander Schacht has made substantial contributions to conception, design, analysis, and interpretation of data; has been involved in drafting the manuscript and revising it critically for important intellectual content; and has given final approval of the version to be published.

Peter Wehmeier has made substantial contributions to conception, design, and interpretation of data; has been involved in revising the manuscript critically for important intellectual content; and has given final approval of the version to be published.

Michael Huss has made substantial contributions to analysis, and interpretation of data; has been involved in drafting the manuscript and revising it critically for important intellectual content; and has given final approval of the version to be published.

Arne Bürger contributed to the data analysis and drafted manuscript. He revised the manuscript for important intellectual content.

\section{ACKNOWLEDGEMENTS}

We wish to thank Birgit Eschweiler, PhD, Medical Writing Services, for editing this manuscript.

\section{REFERENCES}

[1] American Psychiatric Association. (2000) Diagnostic and Statistical Manual of Mental Disorders, $4^{\text {th }}$ ed. Text Revision (DSM-IV-TR). Washington, DC: American Psychiatric Association.

[2] Barkley RA. Major life activity and health outcomes associated with attention-deficit/hyperactivity disorder. J Clin Psychiatry 2002; 63; 10-5

[3] Biederman J, Faraone SV. Attention-deficit hyperactivity disorder. Lancet 2005: 366; 237-48.

[4] Nijmeijer JS, Minderaa RB, Buitelaar JK, Mulligan A, Hartman CA, Hoekstra PJ. Attention-deficit/hyperactivity disorder and social dysfunctioning. Clin Psychol Rev 2008: 28; 692-708.

[5] Escobar R, Hervas A, Soutullo CA, Mardomingo MJ, Uruñuela A, Gilaberte I. Attention-deficit/hyperactivity disorder: burden of the disease according to subtypes in recently diagnosed children [Editorial]. Actas Esp Psiquiatr 2008: 36; 285-94.

[6] Johnston C, Mash EJ. Families of children with attentiondeficit/hyperactivity disorder: review and recommendations for future research. Clin Child Fam Psychol Rev 2001; 4; 183-207.

[7] Sawyer MG, Whaites L, Rey JM, Hazell PL, Graetz BW, Baghurst $\mathrm{P}$. Health-related quality of life of children and adolescents with mental disorders. J Am Acad Child Adolesc Psychiat 2002: 41; 530-7.

[8] Klassen AF, Miller A, Fine S. Health-related quality of life in children and adolescents who have a diagnosis of attentiondeficit/hyperactivity disorder. Pediatrics 2004: 114; e541-e7.

[9] Matza LS, Rentz AM, Secnik K, et al. The link between healthrelated quality of life and clinical symptoms among children with attention-deficit hyperactivity disorder. J Dev Behav Pediatr 2004: $25 ; 166-74$

[10] Escobar R, Soutullo CA, Hervas A, Gastaminza X, Polavieja P, Gilaberte I. Worse quality of life for children with newly diagnosed attention-deficit/hyperactivity disorder, compared with asthmatic and healthy children. Pediatrics 2005: 116; e364-e9.

[11] Riley AW, Spiel G, Coghill D. ADORE Study Group. Factors related to health-related quality of life (HRQoL) among children with ADHD in Europe at entry into treatment. Eur Child Adolesc Psychiatry 2006: 15; i38-i45. 
[12] Jensen PS, Hinshaw SP, Swanson JM, et al. Findings from the NIMH multimodal treatment study of ADHD (MTA): implications and applications for primary care providers. J Dev Behav Pediatr 2001: $22 ; 60-73$.

[13] Banaschewski T, Coghill D, Santosh $\mathrm{P}$, et al. Long-acting medications for the hyperkinetic disorders. A systematic review and European treatment guideline. Eur Child Adolesc Psychiatry 2006: $15 ; 476-95$.

[14] Cheng JY, Chen RY, Ko JS, Ng EM. Efficacy and safety of atomoxetine for attention-deficit/hyperactivity disorder in children and adolescents. Meta-analysis and meta-regression analysis. Psychopharmacology (Berl) 2007: 194; 197-209.

[15] Bastiaens L. Both atomoxetine and stimulants improve quality of life in an ADHD population treated in a community clinic. Psychiatr Q 2008: 79; 133-7.

[16] Hakkart-van Roijen L, Zwirs BW, Bouwmans C, et al. Societal cost and quality of life of children suffering from attention deficient hyperactivity disorder (ADHD). Eur Child Adolesc Psychiatry 2007: 16; 316-26.

[17] Harpin VA. The effect of ADHD on the life of an individual, their family, and community from preschool to adult life. Arch Dis Child 2005: 90; i2-i7.

[18] Riley AW, Spiel G, Coghill D, et al. Factors related to healthrelated quality of life (HRQoL) among children with ADHD in Europe at entry into treatment. Eur Child Adolesc Psychiatry 2006: $15 ; \mathrm{i} 38-\mathrm{i} 45$.

[19] Yang P, Hsu HY, Chiou SS, Chao MC. Health-related quality of life in methylphenidate-treated children with attention-deficit/hyperactivity disorder: results from a Taiwanese sample. Aust $\mathrm{N} \mathrm{Z} \mathrm{J}$ Psychiatry 2007: 41; 998-1004.

[20] Wallander JL, Schmitt M, Koot HM. Quality of life measurements in children and adolescents: issues, instruments, and applications. J Clin Psychol 2001: 57; 571-85.

[21] Riley AW, Robertson J, Forrest CB, Green B, Rebok G, Starfield B. Manual for the Child Health and Illness Profile - Child Edition (CHIP-CE). The Johns Hopkins University, Baltimore MD 2001.

[22] Landgraf JM, Abetz L, Ware JE. The CHQ: A User's Manual (2nd printing). Boston, MA: HealthAct. 1st printing. Boston, MA: The Health Institute 1999, 1996

[23] Perwien AR, Kratochvil CJ, Faries D, et al. Emotional expression in children treated with ADHD medication: development of a new measure. J Atten Disord 2008: 11; 568-79.

[24] American Academy of Pediatrics, Subcommittee on AttentionDeficit/Hyperactivity Disorder and Committee on Quality Improvement. Clinical practice guideline: treatment of the schoolaged child with attention-deficit/hyperactivity disorder. Pediatrics 2001: 108; 1033-44.

[25] Greenhill LL, Pliszka S, Dulcan MK, et al. American academy of child and adolescent psychiatry. Practice parameter for the use of stimulant medications in the treatment of children, adolescents, and adults. J Am Acad Child Adolesc Psychiatry 2002: 41; 26S-49S.

[26] Kratochvil CJ, Vaughan BS, Harrington MJ, Burke WJ. Atomoxetine: a selective noradrenaline reuptake inhibitor for the treatment of attention-deficit/hyperactivity disorder. Expert Opin Pharmacother 2003: 4; 1165-74.

[27] Doherty SL, Frankenberger W, Fuhrer R, Snider V. Children's selfreported effects of stimulant medication. Int J Disabil Dev Educ 2000: $47 ; 39-54$.
[28] Sleator EK, Ullmann RK, von Neumann A. How do hyperactive children feel about taking stimulants and will they tell the doctor? Clin Pediatr (Phila) 1982: 21; 474-9.

[29] Thiruchelvam D, Charach A, Schachar RJ. Moderators and mediators of long-term adherence to stimulant treatment in children with ADHD. J Am Acad Child Adolesc Psychiatry 2001: 40; 9228.

[30] Ibrahim el SR. Rates of adherence to pharmacological treatment among children and adolescents with attention deficit hyperactivity disorder. Hum Psychopharmacol 2002: 17; 225-31.

[31] Charach A, Ickowicz A, Schachar R. Stimulant treatment over five years: adherence, effectiveness, and adverse effects. J Am Acad Child Adolesc Psychiatry 2004: 43; 559-67.

[32] Hazell P. Pharmacological management of attention-deficit hyperactivity disorder in adolescents: special considerations. CNS Drugs 2007: 21; 37-46.

[33] Gau SS, Shen HY, Chou MC, Tang CS, Chiu YN, Gau CS Determinants of adherence to methylphenidate and the impact of poor adherence on maternal and family measures. J Child Adolesc Psychopharmacol 2006: 16; 286-97.

[34] Sanchez RJ, Crismon ML, Barner JC, Bettinger T, Wilson JP. Assessment of adherence measures with different stimulants among children and adolescents. Pharmacotherapy 2005: 25; 909-17.

[35] World Health Organization (WHO). Multiaxial classification of child and adolescent psychiatric disorders: the ICD-10 classification of mental and behavioural disorders in children and adolescents. Cambridge: Cambridge University Press 2004.

[36] World Health Organization (WHO). International Statistical Classification of Diseases, and Related Health Problems. Geneva: World Health Organization 1992; Vol. 1.

[37] Du Paul GJ, Power TJ, Anastopoulos AD, Reid R. ADHD rating scale-IV: checklists, norms, and clinical interpretations. New York: Guilford 1998

[38] Faries DE, Yalcin I, Harder D, Heiligenstein JH. Validation of the ADHD rating scale as a clinician administered and scored instrument. J Atten Disord 2001: 5; 107-15.

[39] Guy W. ECDEU Assessment Manual for Psychopharmacology: Publication ADM 76-338. Washington, DC: US Department of Health, Education and Welfare 1976: 218-22.

[40] National Institutes of Mental Health (NIMH). Psychopharmacol Bull 1985: 21; 839-943.

[41] Wehmeier PM, Schacht A, Dittmann RW, Döpfner M. Global impression of perceived difficulties in children and adolescents with attention-deficit/hyperactivity disorder: reliability and validity of a new instrument assessing perceived difficulties from a patient, parent and physician perspective over the day. Child Adolesc Psychiatr Ment Health 2008: 2; 10.

[42] Wehmeier PM, Schacht A, Dittmann RW, Banaschewski T. Reasons for physicians' choice of medication in medication-naïve patients with ADHD: baseline data of the COMPLY observational study. Curr Drug Ther 2010: 5; 139-50.

[43] Achenbach TM, McConaughy SH, Howell CT. Child/adolescent behavioral and emotional problems: Implications of crossinformant correlations for situational specificity. Psychol Bull 1987: 101; 213-32.

[44] Plück J, Döpfner M, Berner W, et al. Die Bedeutung unterschiedlicher Informationsquellen bei der Beurteilung psychischer Störungen im Jugendalter--ein Vergleich von Elternurteil und Selbsteinschätzung der Jugendlichen. Prax Kinderpsychol Kinderpsychiatr 1997: 46; 566-82. 